\title{
Knowledge, Attitude and Practice of Kangaroo Mother Care among Neonatal Nurses
}

\author{
N. Manzoor (Naheed Manzoor), M. Afzal (Muhammed Afzal), S. Sehar (Sana Sehar), \\ S. A. Gilani (Syed Amir Gilani)
}

University of Lahore, Punjab, Pakistan.

\section{E-mail address:}

naheed.bilal1226@gmail.com

\section{Reprint address:}

Naheed Manzoor

House/No. 302-A,

Mehran Block,

Allama Iqbal Town, Lahore

Punjab, Pakistan

Source: Clinical Social Work and Health Intervention

Volume: 11

Issue: 4

Pages: $46-50$

Cited references: 14

\section{Reviewers:}

Daniel J. West, Jr

University of Scranton, Department of Health Administration and Human Resources, USA

Selvaraj Subramanian

SAAaRMM, Kuala Lumpur, Malaysia

\section{Keywords:}

Kangaroo Mother Care (KMC). Skin to Skin Care (SSC). Knowledge. Attitude. Practices (KAP).

\section{Publisher:}

International Society of Applied Preventive Medicine i-gap

CSWHI 2020; 11(4): 46 - 50; DOI: 10.22359/cswhi_11_4_06 (C) Clinical Social Work and Health Intervention

\section{Abstract:}

Introduction: Kangaroo mother care has been established as having an important role in the care of infants, particularly in preterm and low birth weight infants. Kangaroo mother care implementation depends on knowledge, attitude, and practice by neonatal nurses.

Objectives: To assess the knowledge, attitude and practice of kangaroo mother care among the nurses of neonatology in a tertiary care hospital.

Methods: This study was a descriptive cross sectional study in which data were collected from 38 nurses of neonatology departments. The study respondents were nurses and head nurses. They were assessed through a questionnaire in three domains, knowledge (10 items), attitude (8 items), and practice (4 items). 


\begin{abstract}
Results: In knowledge domain only $32 \%$ nurses knew that kangaroo mother care is a method of care in neonates; $12 \%$ nurses were sure about the components of kangaroo mother care and verbalized these components; $38 \%$ nurses answered that kangaroo mother care is beneficial for low birth weight infants; only $56 \%$ nurses knew about infant position in kangaroo mother care. In attitude domain: $82 \%$ nurses agreed that kangaroo mother care technique is beneficial for infants; $76 \%$ nurses agreed that mothers also were satisfied for adoption of this method. In practice it was observed that 12(32\%) nurses guided and counseled mothers how to practice it.

Conclusions: According to the above results, it is clear that knowledge, practice and attitude, among nurses about kangaroo mother care are at an optimum level after lecture and training intervention. However, there is scope for fulfilling the gaps to get better practices, and training workshops are necessary to bring in behavior change among nurses.
\end{abstract}

\section{INTRODUCTION}

Kangaroo Mother Care (KMC) is defined by World Health Organization as early, continuous and prolonged Skin to Skin Contact (SSC) between the infant and the mother (Guenther et al., 2017). It is an substantiation based technique that is minimizing the morbidity and mortality rate in newly born infants (Chan, Bergelson, Smith, Skotnes, Wall, 2017). KMC has been used as the natural means of body temperature regulation for low birth weight (LBW) infants that is increasingly implemented in the world (Uwaezuoke, 2017). The WHO states that KMC "should be started after clinically stabilizing of a neonate (Morgan et al., 2018). KMC is a nonconventional low income process of infant care (Bera et al., 2014).

Moreover, KMC technique is biologically sound and universally accessible for all infants, particularly for the premature (Heidarzadeh, Hosseini, Ershadmanesh, Gholamitabar Tabari, Khazaee, 2013). The position of a mother in $\mathrm{KMC}$ is vertical or upright. The infant is placed between the breasts of a mother for direct skin to skin contact (Bear \& Mellor, 2017). According to WHO KMC is comprised of 4 basic components that offer: prolonged SSC; exclusive breastfeeding; early discharge from hospital; follow-up (Health, 2003). KMC involves placing the neonate into prolonged and continuous SSC with the mother after birth; breastfeeding; early discharge from hospital; compassionate follow-up at home. Claimed benefits of $\mathrm{KMC}$ as support to the clinical alleviation of several detrimental features of prematurity need to be evidence based (Bear \& Mellor, 2017).

Implementation of any intervention is strongly influenced by attitude (Singh, Mishra, \& Gupta, 2018). It has been pragmatic that despite a number of available evidences about the benefits of kangaroo mother care, the implementation of $\mathrm{KMC}$ is often influenced by the personal knowledge and beliefs of health care providers (Flynn \& Leahy-Warren, 2010). Consequently, the study objective was to assess the knowledge, attitude, and practices (KAP) of kangaroo mother care amongst nurses in a tertiary care hospital.

\section{MATERIALS AND METHODS}

Setting: This was a cross-sectional study conducted in the Neonatal Intensive Care Unit-I \& Unit-II of a tertiary care setup in Lahore, Punjab (Pakistan). The healthcare setup offered facilities such as: outpatient; inpatient; newborn care services.

Population: The nurses from neonatology are directly involved in the care of newborns, they were taken as study respondents to assess the knowledge, attitude, and practice about kangaroo mother care.

Instrument: A questionnaire which comprised on demographic characteristics of the nurses were collected by: age; years of experience in dealing with newborns; education; formal 
training in kangaroo mother care; familiarity with kangaroo mother care. The questionnaire comprised in 3 domains: knowledge (11 items); attitude (8 items); practice (4 items). Closed ended questions were used to evaluate their knowledge and attitudes.

Procedure: Before the study the questionnaire applied on 6 nurses for assessing the gaps and re-structuring it. The pretested questionnaire was applied on 38 nurses of both units (Neonatology unit I \& II).

\section{RESULTS}

The questionnaire was given to 38 nurses including head nurses from the department of neonatology and maternal and reproductive health. All the nurses responded to the questionnaire. The demographic characteristics of the respondents are stated in Table 1.

Table 1: Demographic Characteristics of neonatal nurses

\begin{tabular}{ll}
\hline $\begin{array}{l}\text { Characteristics of } \\
\text { neonatal nurses }\end{array}$ & $\mathrm{n}=38$ \\
\hline $\begin{array}{l}\text { Department (\%) } \\
\text { NNU-I }\end{array}$ & \\
NNU-II & $50 \%$ \\
Age (Mean \pm SD) & $50 \%$ \\
Experience of & $31.03 \pm 1.8$ \\
NNU in year & $12.12 \pm 1.71$ \\
(Mean \pm SD) & \\
Designation (\%) & \\
Head Nurses & \\
Charge Nurses & \\
Training in KMC & $12 \%$ \\
Yes & $88 \%$ \\
No & \\
\end{tabular}

$50 \%$ nurses from NNU-I and 50\% from NNU-II responded. The mean age of participants was $31.03 \pm 1.8$. Work experience (year) in a neonatal nursery unit was $12.12 \mathrm{y} \pm 1.71$. Out of the 38 nurses $6(12 \%)$ were head nurses and $32(88 \%)$ were charge nurses. $16 \%$ of nurses had received formal training in $\mathrm{KMC}$, while $84 \%$ of nurses had no training. All the respondents were female.
Table 2: KAP of nurses about KMC

\begin{tabular}{|c|c|c|}
\hline \multirow[t]{2}{*}{ Sr. \# Questions } & \multicolumn{2}{|c|}{ Responses of Nurses } \\
\hline & Yes & No \\
\hline Knowledge-I & & \\
\hline $\begin{array}{l}\text { 1. Do you know } \\
\text { about KMC? }\end{array}$ & $32 \%$ & $68 \%$ \\
\hline $\begin{array}{l}\text { 2. Do you know about } \\
\text { the components } \\
\text { of KMC? }\end{array}$ & $12 \%$ & $88 \%$ \\
\hline
\end{tabular}

3. Is KMC beneficial $\quad 38 \% \quad 62 \%$

for low birth

weight infants?

4. Does infant in prone $\quad 56 \% \quad 44 \%$ position naked with mother's bare chest?

5. Does mother sit in $\quad 40 \% \quad 60 \%$ an upright position during $\mathrm{KMC}$ ?

6. Is the minimum time $\quad 22 \% \quad 78 \%$ of KMC 1hour?

7. Is the infant dressed $\quad 36 \% \quad 64 \%$ only a diaper during KMC?

8. Is KMC stopped $38 \% \quad 62 \%$ after first complete breastfeeding?

9. Is temperature maintained in the KMC room?

10. Does Nurse help mother to adopt KMC position? Attitude-II

11. Do you agree KMC $\quad 82 \% \quad 18 \%$ is beneficial to preterm infants?

12. Do you agree KMC $\quad 76 \% \quad 24 \%$ is beneficial to mothers?

13. Do you agree KMC $\quad 66 \% \quad 44 \%$ is given by anyone?

14. Do you agree KMC $\quad 72 \% \quad 28 \%$ is started as soon as possible after birth?

15. Do you agree infant can breastfeed in KMC position?

16. Do you agree KMC $\quad 48 \% \quad 52 \%$ can given to infants with oxygen inhalation? 
17. Do you agree KMC is given to ventilator infants?

18. Do you agree KMC has no associated risks?

Practice-III

19. Do you guide the mother about KMC?

20. Do you guide the father about KMC?

21. Do you re-examine the implementation of KMC?

22. Do you use placard, posters, and videos for KMC implementation?

\section{Knowledge regarding KMC in Nurses}

In knowledge domain: only $32 \%$ of nurses knows about the KMC method of care for neonates; $12 \%$ of nurses are sure about the components and verbalized correctly about skin to skin contact of an infant and the mother, early discharge, and supportive follow-up; $38 \%$ of nurses answered that KMC is beneficial for low birth weight infants. Infant is prone naked with mother's bare chest in KMC; $56 \%$ of nurses knew about it; $40 \%$ nurses know about mother's position in KMC; $22 \%$ of nurses know the time duration of KMC; $36 \%$ know about the infant dress up in $\mathrm{KMC}$; $62 \%$ of nurses know that $\mathrm{KMC}$ does not stop after first complete breastfeeding; $48 \%$ of nurses know that KMC room temperature is maintained; $72 \%$ of nurses know that there is need to help mother for adoption of the KMC position (Table 2).

\section{Attitude of Nurses regarding KMC}

The KMC technique is beneficial for the neonate: $82 \%$ of nurses agreed. Mothers also are satisfied for adoption of this method: $76 \%$ of nurses agreed; $66 \%$ of nurses said that KMC can be given by anyone rather than mothers; $72 \%$ of nurses agreed KMC started as soon as possible after birth; $86 \%$ agreed that infant can breastfeed in KMC position; only $48 \%$ of nurses agreed $\mathrm{KMC}$ can be given to infants with oxygen inhalation; only $12 \%$ agreed that KMC can be given with ventilator; $64 \%$ said that $\mathrm{KMC}$ has no associated risks (Table 2).

\section{Practice of Nurses regarding KMC}

It was observed that $12(32 \%)$ nurses guided and counseled mothers about practicing KMC and its benefits and how to do KMC at home; only $28 \%$ guided the father about this technique; $38 \%$ re-examined the infants and their mothers; $42 \%$ explained the method through play cards, posters and videos.

\section{DISCUSSION}

$\mathrm{KMC}$ is a low cost, safe and effective method for the care of LBW infants (Charpak et al., 2005). For the thriving implementation KMC needs supervision, motivation, and care from the healthcare team. Therefore, it is important to assess the KAP of health care professionals for the same. In the current study only $12(32 \%)$ of nurses can define KMC; $12 \%$ correctly knew about components of KMC; $38 \%$ knew the benefits of KMC in LBW infants. A study conducted by Dalal et al. and discovered that $33.1 \%$ of doctors had clear knowledge about KMC; $29.7 \%$ had knowledge about eligible infants (Dalal, Bala, \& Chauhan, 2014). Another study conducted in Kenya elaborated that $87.5 \%$ of health care professionals knew the need of KMC for the LBW infants; $94.3 \%$ knew that KMC practice is through skin to skin contact (Bogonko, 2013). A study conducted in Africa on a staff of nurses affirmed that a majority of nurses had the knowledge of KMC (Solomons \& Rosant, 2012).

Moreover, studies from under-developing countries provided more evidence about KMC adoption. Low birth weight infants can't maintain their body thermo-regulation and remain in hypothermia. According to research, during skin to skin contact LBW infants maintained their body temperature (Charpak et al., 2005). In the present research study, nurses mostly had no formal training; but $82 \%$ agreed that KMC beneficial for the LBW infants; many agreed that skin to skin contact increases the breastfeeding rate, and help mother to bonding with their newly born infants. Dalal et al., stated that $73.8 \%$ of health care professionals had well known about KMC preventing LBW infants from hypothermia; $27.6 \%$ believed that KMC helps to maximize the breastfeeding rate (Dalal et al., 2014). In another study $38.6 \%$ of health care professionals knew that KMC leads toward effective breastfeeding. Therefore, this present study closely related to 
the other studies in regards to basic knowledge and benefits of KMC.

In the present study $36 \%$ of nurses counseled the mothers, while a study conducted by Solomons \& Rosant elaborated that healthcare professionals mostly did not believe there was need of guidance to mothers for adoption KMC method (Solomons \& Rosant, 2012). It is important that mothers are encourged and facilitated by healthcare professionals for practicing KMC which is missed during routine practice. Limitations in the resesrch are due to cross sectional patterns: KAP of nurses regarding KMC; an interventional study in which training and lectures given to staff would be a design to find better results and generalize the findings.

\section{CONCLUSION}

KAP by nurses of neonatology had no optimum level. Nurses know that KMC has several benefits. The proportion of actual practice for the eligible infants is low. Therefore, it is important to held workshops and train nurses on a regular basis for the same reason to increase their knowledge that bring change in attitude and practice.

\section{References:}

1. BEAR RJ, MELLOR DJ (2017) Kangaroo mother care 1: Alleviation of physiological problems in premature infants. The Journal of perinatal education, 26(3), 117-124.

2. BERA A, GHOSH J, SINGH AK., HAZRA, A, MUKHERJEE S, MUKHERJEE, R (2014) Effect of kangaroo mother care on growth and development of low birthweight babies up to 12 months of age: a controlled clinical trial. Acta Paediatrica, 103(6), 643-650.

3. BOGONKO GO (2013).Effect of 'kangaroo mother care'training on knowledge, attitude and practice of health care providers in selected district hospitals in North Rift region, Kenya.

4. CHAN G, BERGELSON I, SMITH ER, SKOTNES, T, WALL S (2017) Barriers and enablers of kangaroo mother care implementation from a health systems perspective: a systematic review. Health Policy and Planning, 32(10), 1466-1475.

5. CHARPAK N, GABRIEL RUIZ J, ZUPAN J, CATTANEO A, FIGUEROA Z, TESSIER R, MENDOZA S (2005) Kangaroo mother care: 25 years after. Acta Paediatrica, 94(5), 514-522.

6. DALAL A, BALA D, CHAUHAN S (2014) A cross-sectional study on knowledge and attitude regarding kangaroo mother care practice among health care providers in Ahmedabad District. Int J Med Sci Public Health, 3(3), 253-256.

7. FLYNN A, LEAHY-WARREN P (2010) Neonatal nurses' knowledge and beliefs regarding kangaroo care with preterm infants in an Irish neonatal unit. Journal of Neonatal Nursing, 16(5), 221-228.

8. GUENTHER T, MOXON S, VALSANGKAR B, WETZEL G, RUIZ J, KERBER K, VIVIO D (2017) Consensus-based approach to develop a measurement framework and identify a core set of indicators to track implementation and progress towards effective coverage of facility-based Kangaroo Mother Care. Journal of global health, 7(2).

9. HEALTH WHO R (2003) Kangaroo mother care: a practical guide: World Health Organization.

10. HEIDARZADEH M, HOSSEINI MB, ERSHADMANESH M, GHOLAMITABAR TABARI M, KHAZAEE S (2013) The Effect of Kangaroo Mother Care (KMC) on Breast Feeding at the Time of NICU Discharge. Iran Red Crescent Med J, 15(4), 302-306. doi: 10.5812/ircmj. 2160

11. MORGAN MC, NAMBUYA, H, WAISWA P, TANN C, ELBOURNE D, SEELEY J, LAWN JE (2018) Kangaro mother care for clinically unstable neonates weighing $\leq 2000$ $\mathrm{g}$ : Is it feasible at a hospital in Uganda? Journal of global health, 8(1).

12. SINGH A, MISHRA N, GUPTA G (2018) Knowledge, attitude, and practice of kangaroo mother care among doctors in a tertiary care hospital from North India. Indian Journal of Child Health, 636-639.

13. SOLOMONS N, ROSANT C (2012) Knowledge and attitudes of nursing staff and mothers towards kangaroo mother care in the eastern sub-district of Cape Town. South African Journal of Clinical Nutrition, 25(1), 33-39.

14. UWAEZUOKE SN (2017) Kangaroo mother care in resource-limited settings: implementation, health benefits, and cost-effectiveness. Res Rep Neol, 7, 11-18. 